\title{
Violência comunitária vivenciada pela população de travestis e mulheres transexuais no Rio de Janeiro: estudo transversal
}

\author{
Community violence experienced by the population of transvestites and transsexual women in Rio \\ de Janeiro: a cross-sectional study \\ Violencia comunitaria vivida por la población de travestis y mujeres transexuales en Río de \\ Janeiro: un estudio transversal
}

Recebido: 20/03/2021 | Revisado: 26/03/2021 | Aceito: 01/04/2021 | Publicado: 09/04/2021

Jesilaine Resende Teixeira Soares ORCID: https://orcid.org/0000-0002-9570-2210 Universidade Federal do Estado do Rio de Janeiro, Brasil E-mail: jeise.r.s.queiroz@gmail.com

Abel Soares de Queiroz Junior ORCID: https://orcid.org/0000-0002-7399-7572 Centro Federal de Educação Tecnológica do Rio de Janeiro, Brasil E-mail: abel.s.q.junior@gmail.com

Virginia Maria de Azevedo Oliveira Knupp

ORCID: https://orcid.org/0000-0001-5512-2863 Universidade Federal do Estado do Rio de Janeiro, Brasil E-mail: virgulaknupp@yahoo.com.br

Eduardo Mesquita Peixoto

ORCID: https://orcid.org/0000-0001-5699-7290 Universidade Federal do Estado do Rio de Janeiro, Brasil E-mail: eduardo.peixoto@ini.fiocruz.br

Lívia Machado de Mello Andrade ORCID: https://orcid.org/0000-0001-9803-5073 Universidade Federal do Estado do Rio de Janeiro, Brasil E-mail: liviammandrade@gmail.com

Flávia de Jesus Neiva Sampaio ORCID: https://orcid.org/0000-0003-4415-8144 Universidade Estácio de Sá, Brasil E-mail: flajns@hotmail.com

Davi Gomes Depret

ORCID: https://orcid.org/0000-0002-7579-789X

Universidade do Estado do Rio de Janeiro, Brasil E-mail: enfodavidepret@gmail.com

Adriana Costa Gil

ORCID: https://orcid.org/0000-0002-8403-8174 Universidade do Estado do Rio de Janeiro, Brasil E-mail: adrianagil.enf @gmail.com

Luciana Catarina Santos de Melo

ORCID: https://orcid.org/0000-0002-6818-573X Universidade Federal do Estado do Rio de Janeiro, Brasil E-mail: lucatarina@yahoo.com.br

Ricardo de Mattos Russo Rafael ORCID: https://orcid.org/0000-0003-1315-4271 Universidade do Estado do Rio de Janeiro, Brasil E-mail: prof.ricardomattos@gmail.com

Luciane de Souza Velasque

ORCID: https://orcid.org/0000-0002-4269-4755 Universidade Federal do Estado do Rio de Janeiro, Brasil

E-mail: luciane.velasque@uniriotec.br

\begin{abstract}
Resumo
Objetivo: analisar a violência comunitária vivenciada por um grupo de travestis e mulheres transexuais no Rio de Janeiro. Metodologia: trata-se de um estudo transversal. A coleta de dados ocorreu de 06/2019 a 03/2020, deu-se presencialmente, através de questionários previamente adaptados, aplicados por entrevistadores treinados. A análise e o processamento dos dados ocorreram por meio do programa de domínio público R (R Foundation for Statistical Computing, versão R-3.5.1), foram realizadas análises univariadas e bivariadas, a inferência foi realizada por meio de teste de normalidade Shapiro-Wilk, em
\end{abstract}


seguida foi escolhido o teste de hipótese adequado que decorrente dos cruzamentos foram: Wilcoxon e Kruskal-Wallis. Resultados: foram realizadas 140 entrevistas, das quais 86 eram travestis $(61,4 \%), 111(79,3 \%)$ não brancas. A maioria tinha estudo a partir do ensino médio 90 (64,3\%), 34 admitiram ser profissionais do sexo (24,3\%), 91 (65\%) são solteiras e 101 moram no município do Rio de Janeiro (72,6\%). A média da idade foi de 35 anos. Foi verificada significância entre a variável desfecho e situação conjugal na análise estatística. Foram encontradas semelhanças na literatura, como escolaridade, etnia e situação conjugal. Conclusão: percebeu-se que nesse grupo a agressão por desconhecidos é superior àquela proferida por conhecidos, que a identidade de gênero é fator preponderante para este tipo de violência.

Palavras-chave: Violência; Agressão; Transfobia; Travestis; Mulheres transexuais.

\begin{abstract}
Objective: to analyze the community violence experienced by a group of transvestites and transsexual women in Rio de Janeiro. Methodology: this is a cross-sectional study. Data collection took place from 06/2019 to 03/2020, in person, through previously adapted questionnaires, applied by trained interviewers. Data analysis and processing took place using the public domain program R (R Foundation for Statistical Computing, version R-3.5.1), univariate and bivariate analyzes were performed, the inference was performed using the Shapiro- normality test. Wilk then chose the appropriate hypothesis test that resulted from the crossings: Wilcoxon and Kruskal-Wallis. Results: 140 interviews were conducted, of which 86 were transvestites (61.4\%), 111 (79.3\%) were non-white. Most had a high school education 90 (64.3\%), 34 admitted to being sex workers (24.3\%), 91 (65\%) are single and 101 live in the city of Rio de Janeiro (72.6\%). The average age was 35 years. Significance was found between the outcome variable and marital status in the statistical analysis. Similarities were found in the literature, such as education, ethnicity and marital status. Conclusion: it was noticed that in this group the aggression by strangers is superior to that given by acquaintances, that gender identity is a preponderant factor for this type of violence.
\end{abstract}

Keywords: Violence; Aggression; Transphobia; Transvestites; Transsexual women.

\title{
Resumen
}

Objetivo: analizar la violencia comunitaria vivida por un grupo de travestis y mujeres transexuales en Río de Janeiro. Metodología: se trata de un estudio transversal. La recogida de datos se realizó del 06/2019 al 03/2020, de forma presencial, a través de cuestionarios previamente adaptados, aplicados por entrevistadores capacitados. El análisis y procesamiento de los datos se llevó a cabo mediante el programa de dominio público R (R Foundation for Statistical Computing, versión R-3.5.1), se realizaron análisis univariados y bivariados, la inferencia se realizó mediante la prueba de normalidad de Shapiro. Prueba de hipótesis que resultó de los cruces: Wilcoxon y Kruskal-Wallis. Resultados: se realizaron 140 entrevistas, de las cuales 86 eran travestis $(61,4 \%), 111(79,3 \%)$ no blancas. La mayoría tenía estudios secundarios de 90 (64,3\%), 34 admitieron ser trabajadoras sexuales $(24,3 \%), 91$ (65\%) son solteras y 101 viven en la ciudad de Río de Janeiro (72,6\%). La edad promedio fue de 35 años. Se encontró significancia entre la variable de resultado y el estado civil en el análisis estadístico. Se encontraron similitudes en la literatura, como educación, etnia y estado civil. Conclusión: se notó que en este grupo la agresión por extraños es superior a la dada por conocidos, que la identidad de género es un factor preponderante para este tipo de violencia.

Palabras clave: Violencia; Agresión; Transfobia; Travestis; Mujeres transexuales.

\section{Introdução}

A violência é um fenômeno com multiplicidade de sentidos, relativo a diversos fatores e causas. Brasil (2017) afirma que, como definição, a OMS (Organização Mundial da Saúde) utiliza o uso intencional de força física ou do poder, real ou em ameaça, contra si próprio ou contra outro. É dividida em três grandes categorias: violência auto infligida, violência interpessoal e violência coletiva. A violência auto infligida é aquela provocada contra si próprio e é subdividida em comportamento suicida e auto abuso. A interpessoal é um conjunto de atos que violam direitos entre as pessoas, é subdividida em: doméstica, quando proveniente de membros da família ou parceiro íntimo que ocorre usualmente nos lares; e comunitária quando a ocorrência se dá entre indivíduos sem relação pessoal que podem ou não se conhecerem. A violência coletiva é aquela praticada por grandes grupos ou pelo próprio Estado e é subdividida de acordo com sua motivação sendo econômica, política ou social (CEVS, 2020).

A violência comunitária ocorre, como já dito, entre pessoas sem vínculos parentescos, sendo conhecidos ou estranhos. Inclui violência entre jovens, atitudes aleatórias de violência, abuso ou ataque sexual por estranhos, bem como a violência em grupos institucionais, como escolas, locais de trabalho, prisões e asilos. Constitui-se por inúmeros tipos de violência que possuem origem nível macro, ou seja, na comunidade onde a qualidade de vida, segurança e saúde formam um 
complexo de existência humana. Esta violência se associa a distintos determinantes sociais, como por exemplo, a criminalidade, desigualdade econômica, dependência de substância, agressividade interpessoal, crime, problemas saúde mental e comportamental, violência originada na escola ou em casa, exposição a cenários de violência dentre outros possíveis exemplos (Pérez Pedrogo, Sánchez Cesáreo, Martínez Taboas, Cólon Jordán \& Morales Boscio, 2016).

A literatura revela que alguns grupos sociais estão vulneráveis a sofrerem cotidianamente atos violentos, a exemplo daqueles considerados estigmatizados, como a população de Lésbicas, Gays, Bissexuais, Travestis e Transexuais (LGBTI) (Parente, Moreira \& Albuquerque, 2018).

Segundo a Política Nacional de Saúde Integral da População LGBTI (Lésbicas, Gays, Bissexuais, Travestis e Transexuais), a orientação sexual e a identidade de gênero são categorias reconhecidas pelo Ministério da Saúde como condicionantes da situação de saúde por expor lésbicas, gays, bissexuais, travestis e transexuais a agravos decorrentes do estigma e da exclusão social (Brasil, 2013).

Transexual é a denominação dada a pessoa que não se identifica com os padrões de gênero definidos previamente para o seu corpo (Souza, 2012). E, no momento em que este reconhecimento com o sexo de nascimento não acontece, ocorre a busca e adaptação conforme o gênero com o qual possui identidade. Esta adaptação ocorre de inúmeras maneiras, dentre elas: vestir-se como sendo do sexo oposto, de maneira a afirmar sua identidade e como a pessoa gostaria de ser reconhecida, transformar-se em momentos distintos, buscar intervenções cirúrgicas e estéticas para mudar o corpo e readequá-lo (Sousa, 2015). O documento Brasil Sem Homofobia define como transgênero "[...] tanto as travestis quanto as transexuais. É um homem no sentido fisiológico, mas se relaciona com o mundo como mulher” (Brasil, 2004).

No âmbito das relações sociais, a discriminação, a violência e a exclusão são relatadas por vários estudos, tanto no Brasil quanto em outros países do mundo, como parte do cotidiano de muitas mulheres transgêneras. Os dados revelam que elas são mais discriminadas do que os gays ou homossexuais, sendo até mesmo discriminadas dentro da comunidade gay. O estigma e a discriminação, por exemplo, estão geralmente associados com a exclusão social, a baixa escolaridade e com as barreiras no acesso ao mercado de trabalho, podendo influenciar a entrada dessas pessoas no mercado sexual e a adoção de comportamentos de risco para doenças e agravos, como o uso de substâncias injetáveis sem orientações médicas e o sexo anal desprotegido com parceiros sexuais; também com desfechos psiquiátricos (como ansiedade e depressão) e uso de substâncias psicoativas (Magno, Dourado \& Silva, 2018).

De acordo com o Saferspaces (2019), a natureza das violências pode ser física, sexual, psicológica e maus tratos/negligência como pode ser observado na figura 1 : 
Figura 1 - Tipologia da violência e suas naturezas

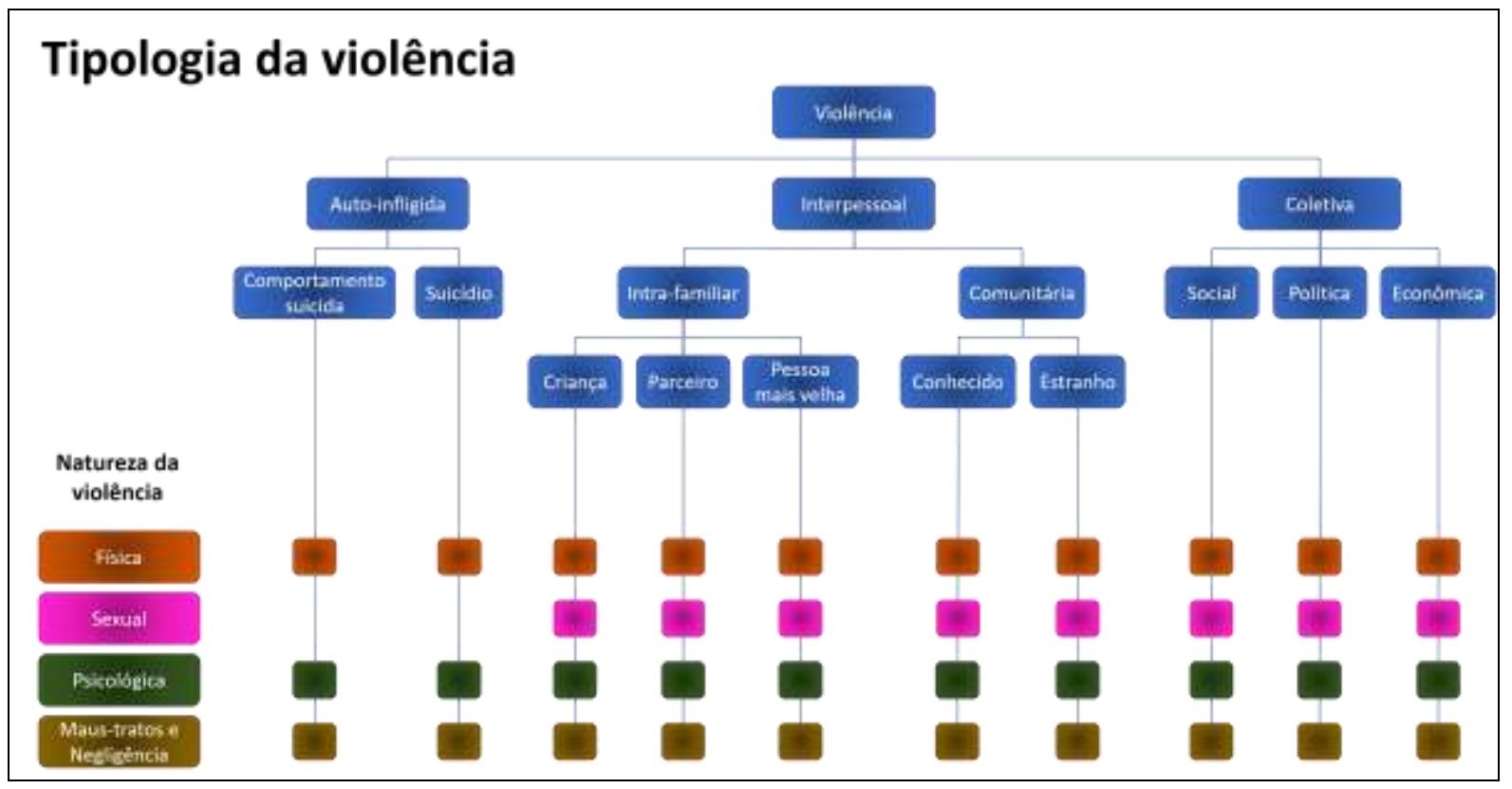

Fonte: Adaptado de Saferspaces (2019).

E, entendendo que a população de travestis e mulheres transexuais está entre as mais sujeitas a sofrer preconceitos, discriminações e violências precisamente por apresentarem identidades de gênero diferentes das determinadas pelos padrões heteronormativos da sociedade (Popadiuk, Oliveira \& Signorelli, 2017), esse estudo visa responder à questão sobre pessoas que se identificam com um gênero distinto daquele que foi estabelecido biologicamente e que fazem parte de um grupo vulnerável da sociedade, com o objetivo de analisar a violência comunitária através da investigação da prevalência dessa violência vivenciada por um conjunto de travestis e mulheres transexuais residentes no Rio de Janeiro e região metropolitana.

\section{Metodologia}

Trata-se de um estudo transversal quantitativo, através do EVAS (Estudo sobre as Violências e a Autoavaliação de Saúde de Mulheres Travestis e Transexuais), com uma população de travestis e mulheres transexuais atendidas no Instituto Nacional de Infectologia da Fundação Oswaldo Cruz (INI-FIOCRUZ). Este estudo adotou como critérios de inclusão: idade igual ou superior a 18 anos, auto identificação como travesti ou mulher transexual que viva na cidade do Rio de Janeiro.

A coleta se deu por meio de entrevista pessoal com questionário previamente formulado sobre diversos tipos de violência, a seção correspondente a violência comunitária foi baseada no questionário da JUVIPOL (Juventude, violência e polícia) do Centro de Estudos de Segurança e Cidadania (CESeC). A coleta ocorreu de 07/2019 a 03/2020. As informações coletadas foram organizadas em planilha eletrônica e processados no Programa R, os resultados foram apresentados em tabelas e gráfico.

Foi realizada a análise descritiva para as variáveis de interesse: faixa etária, raça, escolaridade, situação conjugal, identidade sexual, passabilidade (quando a pessoa é lida ou vista de acordo com o sexo que se identifica e não como o sexo que lhe foi atribuído), profissão e residência.

O desfecho foi a violência comunitária. As variáveis numéricas foram submetidas ao teste de normalidade de Shapiro-Wilk a 5\% para determinar normalidade das distribuições, de acordo com a mesma foi selecionado teste paramétrico 
(T, Anova) ou não paramétrico (Wilcoxon, Kruskal-Wallis). As covariáveis do estudo foram agrupadas em "variáveis sociodemográficas" e "variáveis de violência".

Cada pergunta teve um valor atribuído de acordo com a resposta sendo 0 (zero) para a resposta nunca, 1 (um) para a resposta uma vez, 2 (dois) para a resposta algumas vezes, 3 (três) para a resposta muitas vezes e 99 para não sabe/não respondeu, ou 0 (zero) para a resposta nunca, 1 (um) para a nunca, mas faria se tivesse condições, 2 (dois) para a resposta ás vezes, 3 (três) para a resposta com certeza e 99 para não sabe/não respondeu. A partir da soma dos resultados obtidos em cada variável relacionada à violência foi criada a variável "Escore de violência", o "99" foi substituído por "NULL" para não interferir na soma. E, então foram feitos testes de hipótese entre as variáveis categóricas (sociodemográficas) e a variável violência.

\section{Resultados}

O total de entrevistadas no projeto EVAS foi 140 travestis e mulheres transexuais, das quais 86 eram travestis (61,4\%), 56 com 35 anos ou mais de idade (56,4\%), 111 não brancas (79,3\%), 90 delas com estudo a partir do ensino médio (64,3\%), 34 admitiram ser profissionais do sexo (24,3\%) e 101 moram no município do Rio de Janeiro (72,6\%). Em relação à passabilidade, 65 mulheres consideraram-se bastante passáveis (47,1\%), a média de idade foi de 35 anos, como representado na Tabela 1.

Tabela 1 - Distribuição das variáveis sociodemográficas e passabilidade das travestis e mulheres transexuais. Rio de JaneiroRJ, 2019/2020

\begin{tabular}{|c|c|c|}
\hline Variáveis & Frequência & Frequência \\
\hline Idade & $\mathrm{N}=140$ & $\%$ \\
\hline$<35$ anos & 59 & 42,1 \\
\hline$\geq 35$ anos & 56 & 56,4 \\
\hline Sem iformação & 2 & 1,4 \\
\hline Raça & $\mathrm{N}=140$ & $\%$ \\
\hline Branca & 29 & 20,7 \\
\hline Não branca & 111 & 79,3 \\
\hline Escolaridade & $N=140$ & $\%$ \\
\hline Médio & 90 & 64,3 \\
\hline Fundamental & 50 & 35,7 \\
\hline Situação conjugal & $N=140$ & $\%$ \\
\hline Solteiras & 91 & 65 \\
\hline Namorando/casadas & 49 & 35,0 \\
\hline Como se identificam & $\mathrm{N}=140$ & $\%$ \\
\hline Travesti & 86 & 61,4 \\
\hline Mulher Transexual & 49 & 35,0 \\
\hline Sem informação & 5 & 3,6 \\
\hline Passabilidade & $N=140$ & $\%$ \\
\hline Bastante & 65 & 46,4 \\
\hline Muita & 46 & 32,9 \\
\hline Não Muita & 14 & 10,0 \\
\hline Nenhuma & 13 & 9,3 \\
\hline Sem informação & 2 & 1,4 \\
\hline $\begin{array}{c}\text { É Profissional do } \\
\text { Sexo? }\end{array}$ & $\mathrm{N}=\mathbf{1 4 0}$ & $\%$ \\
\hline Não & 103 & 73,6 \\
\hline Sim & 34 & 24,3 \\
\hline Sem infiormação & 3 & 2,1 \\
\hline Mora no Rio & $\mathrm{N}=\mathbf{1 4 0}$ & $\%$ \\
\hline Sim & 101 & 72,1 \\
\hline Não & 38 & 27,1 \\
\hline Sem informação & 1 & 0,7 \\
\hline
\end{tabular}

Fonte: Elaborado pelos autores (2020). 
$\mathrm{Na}$ análise da violência vivenciada, pode-se destacar que 64 (45,8\%) das entrevistadas já presenciaram "muitas vezes" pessoas andando com arma de fogo na rua que não fossem policiais em serviço e $78(55,8 \%)$ já presenciaram também “muitas vezes” pessoas consumindo ou vendendo drogas ilegais em seu bairro ou comunidade, conforme disposto na Tabela 2.

Tabela 2 - Distribuição das variáveis de violência - Experiências com a violência comunitária - Bloco I. Rio de Janeiro-RJ, $2019 / 2020$

\begin{tabular}{|c|c|c|c|c|c|c|c|c|}
\hline \multicolumn{9}{|c|}{$\begin{array}{l}\text { Nos últimos } 12 \text { meses, você ou alguém da sua família presenciou alguma dessas } \\
\text { situações acontecendo no seu bairro ou comunidade... }\end{array}$} \\
\hline & \multicolumn{2}{|c|}{ Nunca } & \multicolumn{2}{|c|}{ Uma vez } & \multicolumn{2}{|c|}{$\begin{array}{l}\text { Algumas } \\
\text { vezes }\end{array}$} & \multicolumn{2}{|c|}{$\begin{array}{c}\text { Muitas } \\
\text { vezes }\end{array}$} \\
\hline & $\mathrm{N}$ & $\%$ & $\mathrm{~N}$ & $\%$ & $\mathrm{~N}$ & $\%$ & $\mathrm{~N}$ & $\%$ \\
\hline $\begin{array}{l}\text { "Pessoas andando com arma de } \\
\text { fogo na rua que não fossem } \\
\text { policiais em serviço?" }\end{array}$ & 50 & 35,7 & 2 & 1,4 & 22 & 15,8 & 64 & 45,8 \\
\hline $\begin{array}{l}\text { "Pessoas cobrando dinheiro para } \\
\text { dar segurança?" }\end{array}$ & 84 & 60,0 & 2 & 1,4 & 13 & 9,2 & 40 & 28,6 \\
\hline "Pessoas roubando ou furtando?" & 45 & 32,1 & 5 & 3,6 & 28 & 20 & 61 & 43,6 \\
\hline $\begin{array}{l}\text { "Pessoas brigando, agredindo-se } \\
\text { fisicamente?" }\end{array}$ & 41 & 29,2 & 6 & 4,2 & 35 & 25 & 58 & 41,4 \\
\hline $\begin{array}{l}\text { "Pessoas sendo assaltadas nas ruas } \\
\text { da vizinhança?" }\end{array}$ & 65 & 46,2 & 7 & 5 & 21 & 15 & 47 & 33,6 \\
\hline $\begin{array}{l}\text { "Policiais recebendo dinheiro de } \\
\text { pessoas } \\
\text { na vizinhança?" }\end{array}$ & 104 & 74,2 & 2 & 1,4 & 8 & 5,8 & 23 & 16 \\
\hline $\begin{array}{l}\text { "Policiais intimidando ou } \\
\text { agredindo } \\
\text { pessoas na vizinhança?" }\end{array}$ & 81 & 57,9 & 6 & 4,2 & 23 & 16,4 & 28 & 20 \\
\hline $\begin{array}{l}\text { "Pessoas quebrando janelas, } \\
\text { pichando muros, fazendo arruaça ... }\end{array}$ & 81 & 57,9 & 6 & 4,2 & 23 & 16,4 & 29 & 20,8 \\
\hline $\begin{array}{l}\text { "Pessoas consumindo ou vendendo } \\
\text { drogas ilegais na rua?" }\end{array}$ & 39 & 27,9 & 2 & 1,4 & 21 & 15 & 78 & 55,8 \\
\hline
\end{tabular}

Fonte: Elaborado pelos autores (2020).

Na violência física sofrida, 68 (48,6\%) já sofreu agressão por pessoas desconhecidas e 51 (36,4\%) já experimentaram agressões de conhecidos pelo menos uma vez, como pode-se observar na Tabela 3. 
Tabela 3 - Distribuição das variáveis de violência - Experiências com a violência comunitária - Bloco II. Rio de Janeiro-RJ, $2019 / 2020$

\begin{tabular}{|c|c|c|c|c|c|c|c|c|}
\hline \multicolumn{9}{|c|}{$\begin{array}{l}\text { Alguma vez na vida você sofreu } \\
\text { algumas das coisas que vou ler? }\end{array}$} \\
\hline & \multicolumn{2}{|c|}{ Nunca } & \multicolumn{2}{|c|}{ Uma vez } & \multicolumn{2}{|c|}{$\begin{array}{l}\text { Algumas } \\
\text { vezes }\end{array}$} & \multicolumn{2}{|c|}{$\begin{array}{c}\text { Muitas } \\
\text { vezes }\end{array}$} \\
\hline & $\mathrm{N}$ & $\%$ & $\mathrm{~N}$ & $\%$ & $\mathrm{~N}$ & $\%$ & $\mathrm{~N}$ & $\%$ \\
\hline "Alguém lhe ofereceu drogas?" & 17 & 12,1 & 4 & 2,9 & 35 & 25 & 83 & 59,2 \\
\hline $\begin{array}{l}\text { "Você sentiu necessidade de } \\
\text { andar armada?" }\end{array}$ & 79 & 56,4 & 3 & 2,1 & 20 & 14,2 & 37 & 26,2 \\
\hline $\begin{array}{l}\text { "Algum desconhecido a agrediu } \\
\text { fisicamente (tapa, soco, etc)?" }\end{array}$ & 72 & 51,4 & 21 & 15 & 31 & 22,1 & 16 & 11,4 \\
\hline $\begin{array}{l}\text { "Algum amigo(a) ou colega a } \\
\text { agrediu fisicamente?" }\end{array}$ & 89 & 63,6 & 23 & 16,4 & 20 & 14,2 & 8 & 5,8 \\
\hline
\end{tabular}

Fonte: Elaborado pelos autores (2020).

Em relação aos subterfúgios para se defenderem da violência, mais da metade das participantes, 91 (65\%) relataram andar ou andariam se tivessem condições "de táxi” por locais onde passariam a pé se não tivesse o medo da violência e 59 $(42,1 \%)$ evitam andar sozinhas, como exposto na Tabela 4. 
Tabela 4 - Distribuição das variáveis de violência - Experiências com a violência comunitária - Bloco III. Rio de Janeiro-RJ, $2019 / 2020$

\begin{tabular}{|c|c|c|c|c|c|c|c|c|}
\hline \multicolumn{9}{|c|}{$\begin{array}{c}\text { Você faz alguma (s) dessas coisas para se proteger da violência ou sentir-se } \\
\text { mais segura? }\end{array}$} \\
\hline & \multicolumn{2}{|c|}{ Nunca } & \multicolumn{2}{|c|}{$\begin{array}{l}\text { Nunca, } \\
\text { mas faria } \\
\text { se tivesse } \\
\text { condições }\end{array}$} & \multicolumn{2}{|c|}{$\begin{array}{c}\text { Às } \\
\text { vezes }\end{array}$} & \multicolumn{2}{|c|}{$\begin{array}{c}\text { Com } \\
\text { certeza }\end{array}$} \\
\hline & $\mathrm{N}$ & $\%$ & $\mathrm{~N}$ & $\%$ & $\mathrm{~N}$ & $\%$ & $\mathrm{~N}$ & $\%$ \\
\hline "Evita andar sozinha?" & 81 & 57,9 & 7 & 5 & 20 & 14,2 & 32 & 22,9 \\
\hline "Não usa certa(s) linha(s) de ônibus?" & 86 & 61,4 & 10 & 7,1 & 25 & 17,9 & 18 & 12,9 \\
\hline "Deixa de sair de casa à noite?" & 85 & 60,7 & 6 & 4,2 & 16 & 11,4 & 32 & 22,9 \\
\hline "Deixa de ira festas, bares ou boates?" & 94 & 67,1 & 2 & 1,4 & 15 & 10,7 & 28 & 20 \\
\hline "Não sai na comunidade/bairro?" & 100 & 71,4 & 4 & 2,9 & 15 & 10,7 & 19 & 13,6 \\
\hline $\begin{array}{l}\text { "Deixa de frequentar um grupo de } \\
\text { amigos(as) ou colegas?" }\end{array}$ & 87 & 62,1 & 4 & 2,9 & 19 & 13,6 & 26 & 16,8 \\
\hline $\begin{array}{l}\text { "Não volta para casa de } \\
\text { madrugada?" }\end{array}$ & 75 & 53,6 & 9 & 6,4 & 15 & 10,8 & 41 & 29 \\
\hline "Anda de táxi?" & 46 & 32,9 & 22 & 15,8 & 27 & 19,2 & 42 & 30 \\
\hline $\begin{array}{c}\text { "não passa em áreas onde há pessoas } \\
\text { armadas?” }\end{array}$ & 57 & 40,8 & 6 & 4,2 & 15 & 10,8 & 61 & 43,6 \\
\hline “não passa perto da polícia?” & 90 & 64,2 & 7 & 5 & 14 & 10 & 28 & 20 \\
\hline $\begin{array}{l}\text { "Anda com arma branca, tipo faca ou } \\
\text { canivete, para se defender?" }\end{array}$ & 101 & 72,1 & 11 & 7,9 & 16 & 11,4 & 12 & 8,5 \\
\hline $\begin{array}{c}\text { "Anda com arma de fogo para se } \\
\text { defender?" }\end{array}$ & 129 & 92,1 & 7 & 5 & 2 & 1,4 & 2 & 1,4 \\
\hline
\end{tabular}

Fonte: Elaborado pelos autores (2020).

Observa-se que, conforme a figura 2, a análise do boxplot sobre escore de violência comunitária identifica que o valor mínimo foi 3 e o máximo 60, há um outlier de 66, mediana no escore foi de 27 e o desvio padrão foi de 12,2. 
Research, Society and Development, v. 10, n. 4, e30310414155, 2021

(CC BY 4.0) | ISSN 2525-3409 | DOI: http://dx.doi.org/10.33448/rsd-v10i4.14155

Figura 2 - Escore de violência

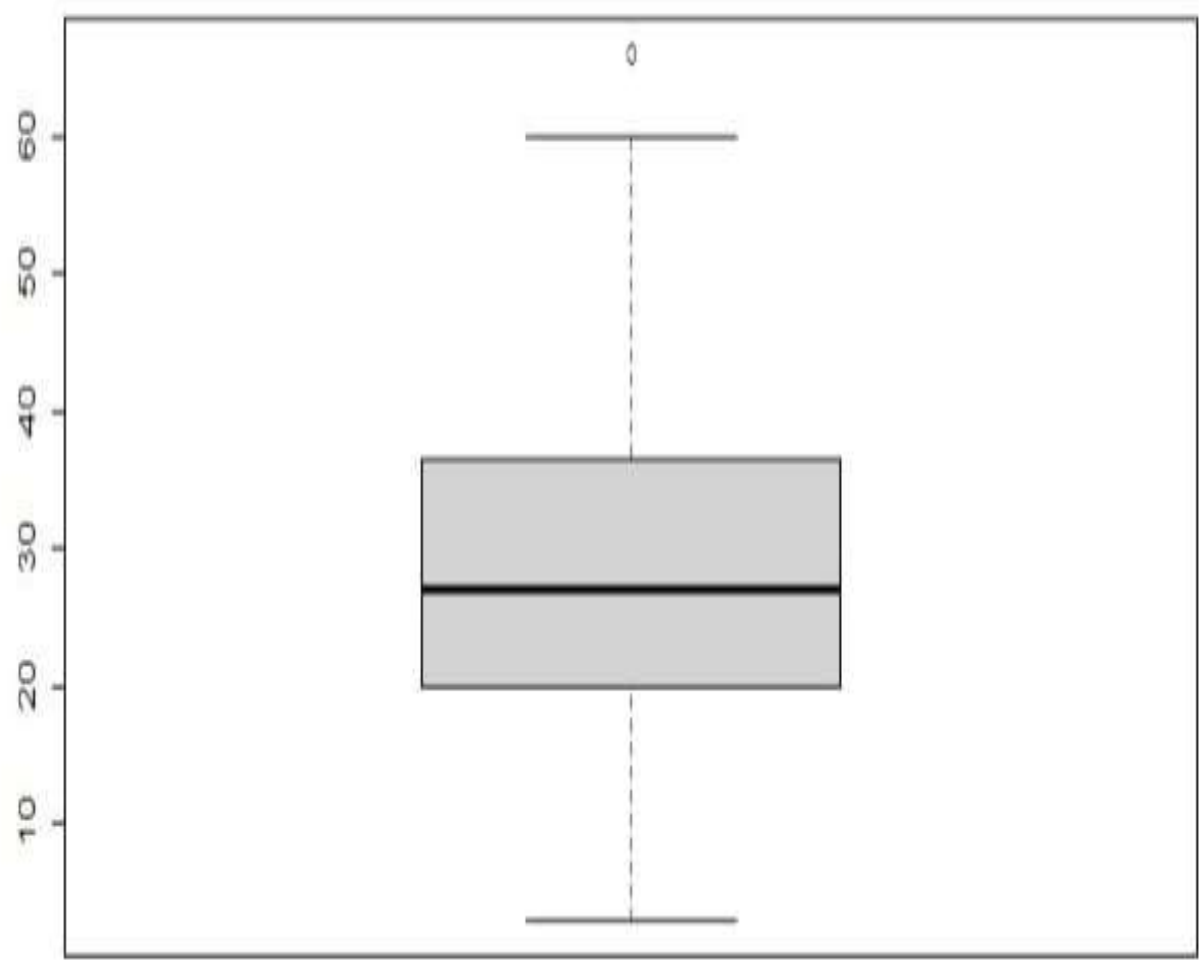

Fonte: Elaborado pelos autores (2020).

$\mathrm{Na}$ análise estatística do desfecho com as variáveis selecionadas, verificou-se significância somente com a variável situação conjugal $(\mathrm{p}=0.02)$ indicando que as pessoas que estão namorando ou amigadas/casadas sofrem menos violência comunitária que as que estão solteiras, como demonstrado na Tabela 5. 
Tabela 5 - Análise estatística das variáveis categóricas X variável violência. Rio de Janeiro-RJ, 2019/2020

\begin{tabular}{|c|c|c|c|}
\hline Variável & Violência & Teste estatístico & P-valor \\
\hline Raça & Mediana & Kruskal-Wallis & 0.272 \\
\hline Branca & 27 & & \\
\hline Não branca & 27 & & \\
\hline Idade & & Kruskal-Wallis & 0.6636 \\
\hline$<35$ anos & 27 & & \\
\hline$\geq 35$ anos & 27 & & \\
\hline \multicolumn{4}{|l|}{ Sem informação } \\
\hline Escolaridade & & Wilcoxon test & 0.2248 \\
\hline Fundamental & 30 & & \\
\hline Médio & 25 & & \\
\hline $\begin{array}{l}\text { Identidade de } \\
\text { gênero }\end{array}$ & & Wilcoxon test & 0.1887 \\
\hline Travesti & 25 & & \\
\hline Mulher trans & 28 & & \\
\hline Passabilidade & & Kruskal-Wallis & 0.0754 \\
\hline Nenhuma & 28 & & \\
\hline Não muito & 23 & & \\
\hline Muito & 24 & & \\
\hline Bastante & 28 & & \\
\hline Mora no Rio & & Kruskal-Wallis & 0.4082 \\
\hline Sim & 26 & & \\
\hline Não & 43 & & \\
\hline Profissional do sexo & & Kruskal-Wallis & 0.2006 \\
\hline Sim & 27,5 & & \\
\hline Não & 26 & & \\
\hline Situação conjugal & & Wilcoxon test & 0.0208 \\
\hline Solteira & 30 & & \\
\hline Namorando/casada & 25 & & \\
\hline
\end{tabular}

Fonte: Elaborado pelos autores (2020).

\section{Discussão}

Os resultados encontrados no presente estudo sobre a média e mediana da idade das entrevistadas são superiores aos valores observados por Silva et al. (2016) que verificou uma média de 23,5 anos e a mediana 23 anos na sua população analisada. No entanto, contrastando aos achados neste estudo cuja média da faixa etária foi de 35 anos, mais semelhante aos dados de outra pesquisa, cuja faixa etária identificada foi entre 20 e 40 anos perfazendo 63,2\% (Magno, Dourado \& Silva, 2018).

A pesquisa de Silva et al. (2016), relatou uma predominância da identidade de gênero travesti, com $81,25 \%$ e n=13 e no estudo de Magno, Dourado \& Silva (2018) também houve uma predominância de 57,9\% dos participantes que se identificaram como travestis, corroborando com os resultados deste estudo, que foram de $61 \%$.

Com relação a etnia, os resultados encontrados são semelhantes aos descritos por Silva et al (2016), onde mais de 90\% das entrevistadas são pardas e negras. Magno, Dourado \& Silva (2018) pontuam que 79\% das participantes não são brancas. Silva et al (2016), em uma análise de etnia, apresentam pardas e negras como maiores representatividades no grupo 
estudado, embora ambas as etnias se apresentem como afrodescendentes, é possível notar que há uma cultura de não reconhecimento da própria origem. De maneira negativa, a falta de informação impacta na equidade preconizada pelo Sistema Único de Saúde (SUS).

$\mathrm{Na}$ análise da escolaridade, verificou-se um padrão semelhante ao descrito nos achados de Silva et al. (2016) e Magno, Dourado \& Silva (2018), nos quais mais da metade das participantes possuíam o ensino médio completo. Outro estudo também traz resultados semelhantes, onde encontra que das pessoas travestis e transexuais participantes 3,2\% completaram apenas o ensino fundamental, 25,8\% o ensino médio e 8,1\% o ensino superior (Bonassi, Amaral, Toneli \& Queiroz, 2015). Bonassi et al. (2015) ainda discutem que 33,9\% pararam de estudar entre os 16 e 19 anos, idade apontada pelos autores como crítica para esta população, pois coincide com o período que as mulheres transexuais e travestis deixaram as casas de suas famílias de origem e passam a se vestir e se "montar" de acordo com o seu gênero.

O baixo nível de escolaridade impacta diretamente a interseção de vulnerabilidades, assim como a baixa renda e profissões com baixa seguridade social. Desta maneira, a vida de travestis e transexuais confronta inúmeras adversidades, e dentre elas a educação, o acesso a serviços de saúde e a geração de renda associada a falta de empregos (Coelho \& Sampaio, 2014). Este fato contribui para a inserção dessa população na prostituição atuando como profissionais do sexo, principalmente no período noturno, que é um fator de risco para as violências. Nessa perspectiva, baixa escolaridade pode ser considerada um fator de risco social com impacto no mercado de trabalho e por sua vez na violência como possível desfecho dessa exposição (Cortes, Silva, Silva \& Soares, 2017).

A pesquisa empreendida pela Elancers, descrita por Sales (2017), revela que há menor presença de mulheres, LGBTIs de etnia negra e, especialmente, transexuais e travestis. Para Yilmaz \& Göçmen (2016), a população de travestis e transexuais estão em uma situação pior quando comparadas ao restante da população LBGTI. Na pesquisa de Zanin, Ferreira \& Ribeiro (2019), 42\% das pessoas entrevistadas tiveram problemas com discriminação na entrada do mercado de trabalho, $21 \%$ das situações foram de problemas resultantes da orientação sexual ou identidade de gênero e foi verificado, também, que um terço dos que encontraram problemas são pessoas transgêneras (travestis e transexuais).

A variável relacionada à vivência da violência comunitária, uma parte significativa das participantes delatam ter sido vítima de algum tipo de violência. Estas importantes informações comprovam intolerância ainda altamente resistente contra as pessoas transgêneros que, por vezes, se traduzem nos inúmeros casos de violência transfóbica relatados pela mídia (Silva et al., 2016). É possível inferir que as condições de saúde das travestis recebem a influência direta das violências sofridas ao longo da vida. A vivência da violência torna-se um fator de afastamento da família e das relações de parentesco, privando estas travestis de um suporte material e das relações afetivas, e, por consequência afasta, também, das escolas e dos serviços de saúde, imprimindo um maior sofrimento a esta população (Souza, Malvasi, Signorelli \& Pereira, 2015).

Uma pesquisa analisando os dados presentes nas notificações de casos de violência, no período de 2015 a 2017 , encontrou registrado no SINAN, 778.527 notificações de violências interpessoais e autoprovocadas, sendo 227.901 em 2015 , 243.259 em 2016 e 307.367 em 2017. Dessas notificações 24.564 foram de violência contra a população LGBTI. O total de $13.129(53,4 \%)$ contra pessoas homossexuais e bissexuais cisgêneros ou com identidade de gênero ignorada, 2.822 (11,5\%) contra travestis e transexuais com orientação homossexual ou bissexual e $8.613(35,1 \%)$ contra travestis e transexuais heterossexuais ou com orientação sexual ignorada (Pinto et al., 2020).

Ainda na questão relacionada à violência, outra pesquisa revela que foi identificado que $75 \%$ das participantes já haviam sofrido algum tipo de violência. Os autores vão além revelando a tipificação da violência sofrida: 91,96\% relataram ter sofrido violência verbal; 58,33\% violência psicológica; 33,33\% violência física e 25\% violência sexual (Silva et al., 2016).

Outro estudo indicou que 73,7\% já tinham sofrido agressão física (Magno, Dourado \& Silva, 2018). Segundo Cortes, Silva, Silva \& Soares (2017), as violências sofridas por travestis e transexuais se apresentam da seguinte forma: com 
$35 \%$ para a violência psicológica, 21\% para a violência física/psicológica, $20 \%$ para discriminação, $13 \%$ a violência não informada, a violência física correspondeu a 7\% e outros tipos de violência representaram 3\%. Estas pesquisas fortalecem nossos resultados onde os entrevistados relatam ter sofrido algum tipo de violência.

Outro estudo com a população LGBTI destaca que, quanto aos tipos de violência sofrida ao longo da vida, observase que as violências psicológicas assumem a primeira posição $(78,8 \%)$ seguidas pelas violências físicas $(31,3 \%)$ e por fim as sexuais $(18,4 \%)$. Os autores também destacam que 1 a cada 1,3 LGBTI sofreu violência psicológica (78,8\% dos participantes), 1 a cada 3,2 LGBTI sofreu violência física (31,3\% dos participantes) e 1 a cada 5,4 LGBTI sofreu violência sexual (18,4\% dos participantes) (Parente, Moreira \& Albuquerque, 2018).

Em relação aos subtipos de violência física, Parente, Moreira e Albuquerque (2018) revelam que os mais frequentes são: os empurrões $(21,8 \%)$ e os socos $(17,4 \%)$. Em último lugar aparece a utilização de armas de fogo $(7,2 \%)$ como extremo da violência, possivelmente associadas às tentativas de homicídios.

Segundo a pesquisa de Pinto et al. (2020), em todas as faixas etárias da população LGBTI a violência física foi a mais prevalente, sendo que contra os adolescentes a violência física e sexual foram as maiores. Nos adultos a violência física e a psicológica e moral foram as mais prevalentes nos adultos. Nos idosos a violência física e negligência e abandono foram as mais identificadas. Ainda de acordo com esta pesquisa, as notificações do SINAN identificaram que em cerca de 24,2\% das notificações os casos de violência foram perpetrados por mais de duas pessoas, sendo a maioria dos agressores do sexo masculino. No caso dos adolescentes e idosos os familiares eram as pessoas que mais agrediam esta população, já para os adultos os agressores intrafamiliares, considerando aqui os parceiros íntimos, sendo os mais prevalentes, seguidos por desconhecidos.

Bonassi, Amaral, Toneli \& Queiroz (2015) também confirmam o exposto por esta pesquisa e a literatura uma vez que, em sua pesquisa, os autores identificam que, no contexto das violências, a maioria assinalou alguma alternativa, sendo que mais de um tipo poderia ser marcado. Os mesmos autores revelaram como alarmante número de pessoas travestis e transexuais vítimas de agressões, preconceitos e negação de direitos. Os autores pontuam que o Brasil se destaca como um dos países com os maiores índices mundiais de violência letal contra esta população.

Nessa mesma pesquisa, de acordo com os resultados de Bonassi et al. (2015), considerando as respostas dadas pelas/os informantes, os subtipos mais citados de violência psicológicas foram: humilhação (68\%), hostilização (55\%), ameaça (56\%), calúnia/injúria/difamação (54\%).

Bonassi et al. (2015) ainda destacam uma informação relevante que é a normalização da violência por parte da própria população LGBTI, onde é possível identificar frases como "mas isso é comum", "isso é todo dia", demonstrando uma naturalização patológica da violência o que é explicado pelo alto grau de situações violentas em que essa população convive. Os autores afirmam isso de acordo com seus resultados que identificam que 55\% das participantes revelaram que sofreram discriminação em decorrência de sua orientação sexual e $66 \%$ por sua identidade de gênero, sendo que $27 \%$ também identificaram terem sido vítimas de bullying.

A violência é um resultado da homofobia, gerando comprometimentos físicos e psicológicos, porém ainda se destaca a violência física, pois a mesma possui duplo impacto na vida desta população, uma vez que a violência física por vezes deixa marcas visíveis, como cicatrizes, o que leva a impactos psicológicos principalmente no âmbito da auto estima e auto imagem (Parente, Moreira \& Albuquerque, 2018).

No presente estudo houve uma associação entre a situação conjugal e a violência, não podendo estabelecer se o fato de estarem acompanhadas de uma figura masculina as deixam menos vulneráveis. Esse fato justifica-se, em parte, pela rede de apoio social e pela figura masculina exercer um papel protetor no cenário da exposição dessa população a violência comunitária. Além disso, o fato de ter um companheiro muda a atuação na prostituição que, em alguns casos, param de atuar 
nessa atividade por vontade própria ou uma solicitação do companheiro. Não foi encontrada na literatura relação entre a violência comunitária e a situação conjugal e mais análises precisam ser realizadas.

A pesquisa como a de Parente, Moreira \& Albuquerque (2018) indica que a maioria dos agressores são pessoas desconhecidas, com destaque para as pessoas na rua, $(13,6 \%)$. Já os agressores conhecidos, tem-se destaque os considerados "amigos" (7,3\%), seguidos por familiares (5,4\%) e ex-companheiros(as) $(3,8 \%)$.

Ainda conforme Parente, Moreira \& Albuquerque (2018), em seu estudo, verificou-se que quanto à situação conjugal, 62,6\% das entrevistadas estavam solteiras e na pesquisa de Silva et al. (2016), 75\% das participantes também estavam solteiras, resultado semelhante a desta pesquisa. Logo, isso pode indicar que a presença de um companheiro/a diminui a chance de acontecer casos de violência perpetrada por desconhecidos.

Outro estudo com a população LGBTI também confirma que as violências psicológicas são mais recorrentes em pessoas desconhecidas na rua. Quanto as evidências relacionadas ao grau de envolvimento entre vítimas e agressores de modo geral, sobressaíram-se as pessoas desconhecidas na rua ( $\mathrm{n}=113,45,4 \%)$, seguido dos conhecidos familiares ( $\mathrm{n}=112,45,0 \%)$ e amigos ( $\mathrm{n}=99,39,8 \%$ ) (Albuquerque, Parente, Belém \& Garcia, 2016).

A cultura negativa relacionada a identidade de gênero está ligada diretamente aos tipos e as formas como essas violências ocorrem, ainda pode-se citar fatores condicionantes de outros marcadores sociais como o gênero, a classe social e a idade (Cortes, Silva, Silva \& Soares, 2017). Sobre essas violências, contra travestis e mulheres transexuais, cerca de 343 pessoas da população LBGT foram assassinadas no Brasil, no ano de 2016, contabilizando um crime de ódio contra essa parcela da população brasileira a cada 25 horas. No ano de 2017, foram contabilizados 296 assassinatos de pessoas LGBTI, no Brasil (Barbosa \& Silva, 2018).

A naturalização dos atos de violência contra a população LGBTI e a omissão social de todos os atores frente a estas situações constituem-se como fatores que perpetuam e disseminam um tipo de violência que, muitas vezes, não é tão escancarado como a violência física, mas que também produz consequências graves, podendo levar suas vítimas a desenvolverem problemas de ordem mental e, em muitos casos, ao suicídio (Albuquerque, Parente, Belém \& Garcia, 2016).

É possível inferir que as condições de saúde das travestis recebem a influência direta das violências sofridas ao longo da vida. A vivência da violência torna-se um fator de afastamento da família e das relações de parentesco, privando-as de um suporte material e das relações afetivas, e, por consequência afasta, também, das escolas e dos serviços de saúde, imprimindo um maior sofrimento a esta população (Souza, Malvasi, Signorelli \& Pereira, 2015).

Com relação as notificações de violência sofridas por esta população, Souza et al. (2015) expõem, em seu estudo, que as delegacias de polícia possuem uma enorme dificuldade na compreensão das queixas apresentadas, isso claro quando há a coragem de se apresentar a uma delegacia. Normalmente as travestis são consideradas ou prejulgadas como culpadas pela situação de violência. Este cenário também se reflete nos serviços de saúde, pois em relação as notificações de violências contra as travestis, entre os anos de 2015 e 2017, foi possível observar que aconteceu uma significativa elevação representando 77,9\% de aumento, correspondendo de 339 em 2015 para 603 em 2017, e destas violências 22,7\% foram contra mulheres transexuais, de 2179 em 2015 para 2673 em 2017 (Magno, Dourado \& Silva, 2018).

Os serviços de saúde são considerados espaços estratégicos para o acolhimento de pessoas em situação de violência. No caso da população LGBTI, é primordial que as equipes de saúde realizem a assistência ao cuidado com um atendimento humanizado e que se tenha em consideração e respeito os marcadores de gênero, raça/cor, etnia e orientação e identidade sexual, para a superação das subjetividades. Portanto, torna-se essencial que sejam oferecidas capacitações e educações permanentes sobre a Política Nacional de Saúde Integral de Lésbicas, Gays, Bissexuais e Transgênersos (PNSILGBTI) nos serviços de saúde com intuito de sensibilizar os profissionais levando-os a compreensão e reflexão sobre a importância do 
preenchimento correto e completo da ficha de notificação no enfrentamento à violência sofrida por esta população (Pinto et al., 2020).

Considerando o discutido acima e o expresso na literatura é importante destacar que as violências simbólicas e interpessoais vividas pela população LGBTIs são experenciadas de formas diferentes por cada um. As situações de violência se expressam de forma específica em cada uma das identidades sexuais, como por exemplo, a violência interpessoal vivida no trabalho pelas lésbicas e transexuais é diferente da vivenciada pelas travestis, uma vez que o emprego formal é muito mais possível na realidade das primeiras que na das travestis. Ainda é importante ressaltar que, além da violência perpetuada por pessoas heterossexuais, há também as situações de violência perpetradas pela própria população não heterossexual, que acaba reproduzindo o ponto de vista de uma sociedade heteronormativa, mesmo que de forma não intencional. Assim a literatura reforça a necessidade da condução de estudos que busquem compreender profundamente a organização social e particularidades desta população (Carrieri, Souza \& Aguiar, 2014).

\section{Conclusão}

Diante do exposto através de informações, dados e fatos analisados percebe-se a relevância da temática e que seja urgente a de organizar redes de atenção à saúde a população de travestis, na verdade a população LGBTI. Esta rede de atenção deve instaurar como objetivo e implementação real o princípio da equidade para estes indivíduos com a elevação da qualidade de vida na comunidade. E, que se favoreça e respeite a diversidade sexual associando uma desconstrução do estigma vivenciado pelas travestis e mulheres transexuais e para que possam ser as autoras de suas histórias.

O cenário de violência e sofrimento social refletido permite inferir que há ainda um árduo caminho a percorrer para a quebra do paradigma da violência. Um bom primeiro degrau a se superar poderia ser uma incrementação da formação dos profissionais que atendem as travestis, em especial, a formação dos profissionais de saúde. O debate e a discussão sobre sexualidade, gênero e diferença fazem-se necessários e urgentes.

Não existe dúvida que a academia com a produção de conhecimento bem como a necessária disseminação destas informações corresponde a uma das ferramentas mais poderosas para a compreensão da violência vivenciada pelas travestis e mulheres transexuais. Uma vez assimilada a complexidade deste tema torna-se viável um enfrentamento destas discriminações e, por conseguinte, é possível visualizar uma redução das violências.

$\mathrm{Na}$ violência efetuada contra esta população, acentuou-se que o silenciamento das agressões sofridas e sua invisibilidade no contexto social e institucional reflete a inibição dos direitos humanos e o ocultamento da realidade.

\section{Referências}

Albuquerque, G. A., Parente, J. S., Belém, J. M. \& Garcia, C. L. (2016). Violência psicológica em lésbicas, gays, bissexuais, travestis e transexuais no interior do Ceará, Brasil. Saúde Debate, 40(109), 100-111. doi: 10.1590/0103-1104201610908.

Barbosa, B. R. S. N., Silva, L. V. (2018). Transexualidade, violência e ciberespaço: um estudo etnográfico digital. Percurso Acadêmico, 7(14), 419-435. doi: https://doi.org/10.5752/P.2236-0603.2017v7n14p419-435.

Bonassi, B. C., Amaral, M. S., Toneli, M. J. F. \& Queiroz, M. A. (2015). Vulnerabilidades mapeadas, violências localizadas: experiências de pessoas travestis e transexuais no Brasil. Quaderns de Psicologia, 17(3), 1-16. doi: https://doi.org/10.5565/rev/qpsicologia.1283.

Brasil. (2004). Ministério da Saúde. Conselho Nacional de Combate à Discriminação. Brasil sem homofobia: programa de combate à violência e à discriminação contra GLTB e promoção da cidadania homossexual. Brasília: Ministério da Saúde. Recuperado de: https://bvsms.saude.gov.br/bvs/publicacoes/brasil_sem_homofobia.pdf.

Brasil. (2013). Ministério da Saúde. Secretaria de Gestão Estratégica e Participativa, Departamento de Apoio à Gestão Participativa. Política nacional de saúde integral de lésbicas, gays, bissexuais, travestis e transexuais. Brasília: Ministério da Saúde. Recuperado de: https://bvsms.saude.gov.br/bvs/publicacoes/politica_nacional_saude_lesbicas_gays.pdf. 
Brasil. (2016). Ministério da Saúde. Secretaria de Gestão Estratégica e Participativa, Departamento de Apoio à Gestão Participativa. Atenção Integral à Saúde da População Trans. Conteúdo para do profissionais de SUS. Brasília: Ministério da Saúde. Recuperado de: http://portalarquivos2.saude.gov.br/images/pdf/2016/fevereiro/18/CARTILHAEquidade-10x15cm.pdf.

Brasil. (2017). Secretaria de Saúde do Distrito Federal. Vigilância em Violência. Brasília: Ministério da Saúde. Recuperado de: http://saude.df.gov.br/vigilancia-em-violencia/.

Brasil. (2018). Governo do Estado de São Paulo. Secretaria da Justiça e da Defesa da Cidadania. Diversidade sexual e cidadania LGBT. São Paulo: Governo do Estado de São Paulo. Recuperado de: http://justica.sp.gov.br/wp-content/uploads/2017/07/Cartilha-3a-Edi\%C3\%A7\%C3\%A3o-Final.pdf.

Carrieri, A. P., Souza, E. M. \& Aguiar, A. R. C. (2014). Trabalho, violência e sexualidade: estudo de lésbicas, travestis e transexuais. Revista de Administração Contemporânea, 18(1), 78-95. doi: 10.1590/S1679-39512013000100011.

CEVS. (2020). Tipologia da violência. Recuperado de: https://www.cevs.rs.gov.br/tipologia-da-violencia.

Coelho, M. T. A. D. \& Sampaio, L. L. P. (2014). Transexualidades: um olhar multidisciplinar. Salvador: EDUFBA.

Cortes, G. R., Silva, L. F., Silva, L. K. R. \& Soares, G. S. (2017). Violência contra travestis e transexuais: a mediação da informação no espaço LGBT. 18 Encontro Nacional de Pesquisa em Ciência da Informação (pp. 1-21). Marília: Universidade Estadual Paulista.

Costa, A. B. \& Nardi, H. C. (2015). Homofobia e Preconceito contra Diversidade Sexual: Debate Conceitual. Temas em Psicologia, 23(3), 715-726. doi: http://dx.doi.org/10.9788/TP2015.3-15.

Magno, L., Dourado, I., \& Silva, L. A. V. (2018). Estigma e resistência entre travestis e mulheres transexuais em Salvador. Cad. Saúde Pública, 34(5), 1-12. doi: https://doi.org/10.1590/0102-311x00135917.

Pereira, L. B. C. \& Chazan, A. C. S. (2019). O Acesso das Pessoas Transexuais e Travestis à Atenção Primária à Saúde: uma revisão integrativa. Revista Brasileira de Medicina de Família e Comunidade, 14(41): 1795. https://doi.org/10.5712/rbmfc14(41)1795.

Parente, J. S., Moreira, F. T. L. S. \& Albuquerque, G. A. (2018). Violência física contra lésbicas, gays, bissexuais, travestis e transexuais no interior do nordeste brasileiro. Rev. Salud Pública, 20(4), 1-8. doi: https://doi.org/10.15446/rsap.V20n4.62942.

Pérez Pedrogo, C., Sánchez Cesáreo, M., Martínez Taboas, A., Cólon Jordán, H. \& Morales Boscio, AM. (2016). Violencia comunitaria: Programas basados en la evidencia como alternativa para su mitigación. Revista Puertorriqueña de Psicología, 27(1), 26-42.

Pinto, I. V., Andrade, S. S. A., Rodrigues, L. L., Santos, M. A. S., Marinho, M. M. A., Benício, L. A., Correia, R. S. B. \& Canavese, D. (2020). Perfil das notificações de violências em lésbicas, gays, bissexuais, travestis e transexuais registradas no Sistema de Informação de Agravos de Notificação, Brasil, 2015 a 2017. Rev. Bras. de Epidemiol., 23: E200006, 1-13. doi: 10.1590/1980-549720200006.supl.1.

Pontes, J. C. \& Silva, C. G. (2017). Cisnormatividade e passabilidade: deslocamentos e diferenças nas narrativas de pessoas trans. Revista Periodicus, 1(8), 396-417. doi: 10.9771/peri.v1i8.23211.

Popadiuk, G. S., Oliveira, D. C. \& Signorelli, M. C. (2017). A Política Nacional de Saúde Integral de Lésbicas, Gays, Bissexuais e Transgêneros (LGBT) e o acesso ao Processo Transexualizador no Sistema Único de Saúde (SUS): avanços e desafios. Ciênc. Saúde coletiva, 22(5), 1509-1520. doi: https://doi.org/10.1590/1413-81232017225.32782016.

Saferspaces. (2019). O que é violência?. Recuperado de: https://www.saferspaces.org.za/understand/entry/what-is-violence.

Sales, R. G. (2017). Políticas de respeito à diversidade sexual no ambiente de trabalho: análise das percepções sobre o papel da comunicação em organizações participantes do Fórum de empresas e direitos LGBT. (Dissertação de Mestrado). Universidade de São Paulo, São Paulo, SP, Brasil.

Silva, G. W. S., Souza, E. F. L., Sena, R. C. F., Moura, I. B. L., Sobreira, M. V. S., \& Miranda, F. A. N. (2016). Situações de violência contra travestis e transexuais em um município do nordeste brasileiro. Rev Gaúcha Enferm., 37(2), 1-7. doi: http://dx.doi.org/10.1590/1983- 1447.2016.02.56407.

Souza, M. H. T., Malvasi, P., Signorelli, M. C. \& Pereira, P. P. G. (2015). Violência e sofrimento social no itinerário de travestis de Santa Maria, Rio Grande do Sul, Brasil. Cad. Saúde Pública, 31(4), 767-776. doi: https://doi.org/10.1590/0102-311X00077514.

Sousa, P. F. (2015). Há diferenças entre travestis e transexuais femininas? Breve conceituação dos termos (Monografia). Faculdade Cearense - FAC, Fortaleza, CE, Brasil.

Souza, M. H. T., Malvasi, P., Signorelli, M. C. \& Pereira, P. P. G. (2015). Violência e sofrimento social no itinerário de travesties de Santa Maria, Rio Grande do Sul, Brasil. Cad. Saúde Pública, 31(4), 767-776. doi: https://doi.org/10.1590/0102-311X00077514.

Souza, H. A. (2012). Os desafios do trabalho na vida cotidiana de mulheres transexuais. (Dissertação de Mestrado). PUC-Campinas, Campinas, SP, Brasil.

Yilmaz, V. \& Göçmen, I. (2016). Denied citizens of Turkey: Experiences of discrimination among LGBT individuals in employment, housing and health care, New Jersey, Gender, Work \& Organization, 23(5), 470-488.

Zanin, H. S. Ferreira, L. S. \& Ribeiro, L. P. (2019). Ingresso e permanência no trabalho e emprego por sujeitos LGBT+ em Belo Horizonte, Brasil. Id Online Revista Multidisciplinar e de Psicologia, 23(44), 460-474. 